\title{
Radiocesium concentrations in wild mushrooms collected in Kawauchi Village after the accident at the Fukushima Daiichi Nuclear Power Plant
}

Kanami Nakashima, Makiko Orita, Naoko Fukuda, Yasuyuki Taira, Naomi Hayashida, Naoki Matsuda, Noboru Takamura

It is well known from the experience after the 1986 accident at the Chernobyl Nuclear Power Plant that radiocesium tends to concentrate in wild mushrooms. In this study, we collected wild mushrooms from the Kawauchi Village of Fukushima Prefecture, located within $30 \mathrm{~km}$ of the Fukushima Daiichi Nuclear Power Plant, and evaluated their radiocesium concentrations to estimate the risk of internal radiation exposure in local residents. We found that radioactive cesium exceeding $100 \mathrm{~Bq} / \mathrm{kg}$ was detected in 125 of 154 mushrooms (81.2\%). We calculated committed effective doses based on 6,278 grams per year (age $>20$ years, 17.2g/day), the average intake of Japanese citizens, ranging from doses of 0.11-1.60 mSv, respectively. Although committed effective doses are limited even if residents eat contaminated foods several times, we believe that comprehensive risk-communication based on the results of the radiocesium measurements of food, water, and soil is necessary for the recovery of Fukushima after this nuclear disaster. 
1 Radiocesium Concentrations in Wild Mushrooms Collected in Kawauchi Village after the

2 Accident at the Fukushima Daiichi Nuclear Power Plant

3

4 Kanami Nakashima ${ }^{1}$, Makiko Orita ${ }^{1}$, Naoko Fukuda ${ }^{2}$, Yasuyuki Taira ${ }^{3}$, Naomi Hayashida ${ }^{4}$,

5 Naoki Matsuda ${ }^{5}$, and Noboru Takamura ${ }^{1 *}$

$6{ }^{1}$ Department of Global Health, Medicine, and Welfare

$7 \quad{ }^{2}$ Department of Radioisotope Medicine

$8 \quad{ }^{3}$ Nagasaki Prefectural Pharmaceutical Affairs

$9{ }^{4}$ Division of Strategic Collaborative Research Center for Promotion of Collaborative Research

10 on Radiation and Environment Health Effects

$11{ }^{5}$ Department of Radiation Biology and Protection, Atomic Bomb Disease Institute, Nagasaki

12 University Graduate School of Biomedical Sciences

13 *Correspondence to: Noboru Takamura, M.D., Ph.D.

14 Professor and Chairman,

15 Department of Global Health, Medicine and Welfare, Atomic Bomb Disease Institute, Nagasaki

16 University Graduate School of Biomedical Sciences

17 1-12-4 Sakamoto, Nagasaki 852-8523, Japan

18 Tel: $+81-95-819-7170$ 
19 Fax: +81-95-819-7172

20 E-mail: takamura@nagasaki-u.ac.jp 


\section{Abstract}

23 It is well known from the experience after the 1986 accident at the Chernobyl Nuclear Power

24 Plant that radiocesium tends to concentrate in wild mushrooms. In this study, we collected wild mushrooms from the Kawauchi Village of Fukushima Prefecture, located within $30 \mathrm{~km}$ of the Fukushima Daiichi Nuclear Power Plant, and evaluated their radiocesium concentrations to estimate the risk of internal radiation exposure in local residents. We found that radioactive cesium exceeding $100 \mathrm{~Bq} / \mathrm{kg}$ was detected in 135 of 154 dried mushrooms (87.7\%). Interestingly, 17 species showed relatively higher concentrations of radiocesium and five species showed relatively lower concentrations. We calculated committed effective doses based on 16.1 grams

31 per day and 5,876.5 grams per year (the average intake of Japanese citizens), ranging from doses of $0.256-3.748 \mu \mathrm{Sv}$ and $0.093-1.368 \mathrm{mSv}$, respectively. Although committed effective doses are

33 relatively limited even if residents eat contaminated foods several times, we believe that 34 comprehensive risk-communication based on the results of the radiocesium measurements of

35 food, water, and soil is necessary for the recovery of Fukushima after this nuclear disaster. 


\section{Introduction}

On March 11, 2011, a 9.0-magnitude earthquake struck the east coast of Iwate, Miyagi, and

39 Fukushima Prefectures in Japan. The earthquake, in combination with the resulting tsunami,

40 triggered a severe nuclear accident at the Fukushima Daiichi Nuclear Power Plant (FNPP)

41 (IAEA, 2011a; IAEA, 2011b). Due to this accident, large amounts of radionuclides, including

42 iodine-131 $\left({ }^{131} \mathrm{I}\right)$, cesium-134 $\left({ }^{134} \mathrm{Cs}\right)$, and cesium-137 $\left({ }^{137} \mathrm{Cs}\right)$ were released into the atmosphere

43 (UNSCEAR, 2013). The United Nations Scientific Committee on the Effects of Atomic

44 Radiation (UNSCEAR) estimated the total release of ${ }^{131} \mathrm{I},{ }^{134} \mathrm{Cs}$, and ${ }^{137} \mathrm{Cs}$ at $120.0,9.0$, and 8.8

45 petabecquerel (PBq), respectively.

46 To minimize the internal radiation exposure of local residents, Japanese national and prefectural

47 governments began to monitor selected foodstuffs (milk, vegetables, grains, meat, fish, etc.) on

48 March 16, 2011. Those containing radioactive material that exceeded the provisional regulation

49 values as recommended on March 17, 2011, by Japan's Ministry of Health, Labour and Welfare

50 (MHLW) were prohibited from distribution on March 21, 2011, and from consumption on March

51 23, 2011 (Hamada, Ogino \& Fujimichi, 2012; Merz, Steinhauser \& Hamada, 2013; Merz,

52 Shozugawa \& Steinhauser, 2015). Due to this stringent food-control policy, internal radiation

53 from radioactive cesium and radioactive iodine was relatively limited (Harada et al., 2012;

54 Koizumi et al., 2012; Hayano et al., 2013). Fukushima Prefecture reported the results of internal 
55 radiation doses measured with a whole-body counter in residents of Fukushima Prefecture and its

56 evacuees from June 2011 to February 2015. Of these, 233,199 (99.9\%) showed a committed

57 effective dose of $<1 \mathrm{mSv}$; the maximum recorded level was $3 \mathrm{mSv}$, which was measured in two

58 individuals (Taira et al., 2014).

59 However, based on the experience after the 1986 accident at the Chernobyl Nuclear Power Plant,

60 it is well known that radiocesium tends to concentrate in wild mushrooms (Skuterud et al., 1997;

61 Jesko et al., 2000; Hille et al., 2000; Hoshi et al., 2000; Travnikova et al., 2001; Sekitani et al.,

62 2010; Guillén \& Baeza, 2014). Hoshi et al. reported that children consuming mushrooms showed

63 a relatively high ${ }^{137} \mathrm{Cs}$ body burden near Chernobyl, which suggests that mushrooms are one of

64 the main contributors to internal radiation exposure from radiocesium after nuclear disasters

65 (Hoshi et al., 2000). Although the evaluation of radiocesium concentrations in wild mushrooms

66 is important, comprehensive studies have not been conducted to measure the concentrations of

67 radiocesium in mushrooms in a certain area and to clarify the risk of internal exposure in the residents of Fukushima. In this study, we collected wild mushrooms from the Kawauchi Village of Fukushima Prefecture, located within $30 \mathrm{~km}$ of the FNPP (Fig. 1), and evaluated their radiocesium concentrations to estimate the internal radiation exposure of local residents. 


\section{Materials \& Methods}

73

74

75

76

77

\section{Sampling of Mushrooms}

Prior to the study, we obtained approval from the Kawauchi Village Office (Approval Number: 20130120). Wild mushrooms were collected in Kawauchi Village (at the public office, N37 $20^{\circ}$, E140 $48^{\prime}$ ), located within $30 \mathrm{~km}$ of the FNPP, from September through November 2013, 30-32 months after the accident. In cooperation with the residents of the village, we collected 154 mushroom samples from a total of 22 species.

After collection, all samples were dried in a fixed-temperature dryer $\left(60^{\circ} \mathrm{C}\right.$ for $24 \mathrm{~h}$, then $105^{\circ} \mathrm{C}$ for $1 \mathrm{~h})$. They were then placed in plastic containers made of polypropylene and analyzed with a highpurity germanium detector $\left(\mathrm{ORTEC}^{\circledR}, \mathrm{GMX}^{\mathrm{B}}\right.$-70, Ortec International Inc., Oak Ridge, TN, USA) coupled with a multi-channel analyzer (MCA7600, Seiko EG\&G Co., Ltd., Chiba, Japan) for 3,600

s. The measuring time was set to detect the objective radionuclide, and the gamma-ray peaks used for the measurements were $604.66 \mathrm{keV}$ for ${ }^{134} \mathrm{Cs}(2.1 \mathrm{y})$ and $661.64 \mathrm{keV}$ for ${ }^{137} \mathrm{Cs}(30 \mathrm{y})$. Decay corrections were made based on the sampling date, and detector efficiency calibration was performed for different measurement geometries using mixed-activity standard volume sources (Japan Radioisotope Association, Tokyo, Japan). All measurements were performed at Nagasaki University (Nagasaki, Japan). The sum of ${ }^{134} \mathrm{Cs}$ and ${ }^{137} \mathrm{Cs}$ concentrations was indicated as "concentrations of radiocesium." For the six mushrooms in which only ${ }^{137} \mathrm{Cs}$ was detected, 
90 concentrations of ${ }^{137} \mathrm{Cs}$ were indicated as "concentrations of radiocesium." To calculate the

91 committed effective doses, we calculated the ratio of radiocesium concentrations in dried and raw

92 mushrooms using 81 samples of Sarcodon aspratus, and found that it was 1:8 (data not shown).

94 Committed Effective Dose

95 The committed effective dose from mushroom concentration intake was calculated using the

96 following formula:

$$
\text { Hint }=C \cdot \operatorname{Dint} \cdot e
$$

where $C$ is the activity concentration (median) of detected artificial radionuclides (radiocesium) for ${ }^{134} \mathrm{Cs}$ and $1.3 \times 10^{-5} \mathrm{mSv} / \mathrm{Bq}$ for ${ }^{137} \mathrm{Cs}$ ) (ICRP, 1995), and $e$ is the daily intake value (17.2 $\mathrm{g} / \mathrm{day}$, the average intake of Japanese citizens) (MHLW, 2012). 
103

104

105

106

107

108

109

110

111

112

113

114

115

116

117

118

119

\section{Results}

The species and amounts of the collected wild mushrooms are listed in Table 1. Among the 154 mushroom samples from 22 species, 79 (51.3\%) were Sarcodon aspratus, 11 (7.1\%) were Hypholoma sublateritium, and $10(6.5 \%)$ were Armillaria mellea. The concentrations of radiocesium $\left({ }^{134} \mathrm{Cs}+{ }^{137} \mathrm{Cs}\right)$ in the dried mushrooms are shown in Fig. 2. Radiocesium was not detected in 19 mushrooms (12.3\%); however, 1,000-9,999 Bq/kg of radiocesium was detected in 86 mushrooms $(55.8 \%)$, and $>10,000 \mathrm{~Bq} / \mathrm{kg}$ of radiocesium was detected in 36 mushrooms (23.4\%). The maximum concentration was $124,900 \mathrm{~Bq} / \mathrm{kg}$ in Cortinarius salor Fr.

The concentration of radiocesium of each species is shown in Table 1. Radiocesium was detected in 79 of 79 samples (100\%) of Sarcodon aspratus, 10 of 11 samples (90.9\%) of Hypholoma sublateritium, 8 of 10 samples (80\%) of Armillaria mellea, 6 of 6 samples (100\%) of Tricholoma matsutake, and 6 of 6 samples (100\%) of Pholiota microspora. However, radiocesium was not detectable in Grifola frondosa $(N=3)$, Lentinula edodes $(N=1)$, Armillaria tabescens $(N=1)$, and Entoloma sarcopum $(N=1)$. Seventeen species showed relatively higher concentrations of radiocesium, including nine species of mycorrhizal fungus and eight species of root fungus. However, five species showed relatively lower concentrations of radiocesium.

Next, we mapped the distribution of mushrooms with concentrations of radiocesium in Kawauchi 
120 Village (Fig. 3). The calculated committed effective doses are shown in Table 2. These were

121 calculated assuming 16.1 grams of raw mushrooms per day and 5,876.5 grams per year (the

122 average intake of Japanese citizens). Among the 135 dried mushrooms $(87.7 \%)$ that contained

123 radiocesium exceeding $100 \mathrm{~Bq} / \mathrm{kg}$, the minimum and maximum calculated daily and annual

124 committed effective doses ranged from $0.256-3.748 \mu \mathrm{Sv} /$ day and $0.093-1.368 \mathrm{mSv} / \mathrm{year}$,

125 respectively.

126

127 Discussion

128 In this study, radioactive cesium exceeding $100 \mathrm{~Bq} / \mathrm{kg}$ was detected in 135 of $154(87.7 \%)$ dried

129 mushrooms collected in Kawauchi Village, Fukushima Prefecture. Kawauchi Village is located

$130 \quad 20-30 \mathrm{~km}$ southwest of the FNPP, and most of its residents were evacuated during the initial phase

131 of the accident at the FNPP. On January 31, 2012, the head of Kawauchi Village declared that

132 residents who lived at least $20 \mathrm{~km}$ away from the FNPP could return to their homes, after the

133 Japanese Prime Minister declared that the FNPP reactors had achieved a state of "cold shutdown"

134 in December 2011 (Orita et al., 2013). Since this declaration, the village office has been working

135 steadily towards reconstruction, including decontamination within the village. Decontamination of

136 residential houses has been conducted since mid-2011, even within the $20 \mathrm{~km}$ radius of the FNPP. 
137 However, decontamination has not been conducted in the forests of Fukushima Prefecture,

138 including Kawauchi Village. Therefore, because all of the mushrooms in this study were collected

139 in the forest around the village, high frequencies of radiocesium were detected.

140 Since the Chernobyl accident, a series of studies has been conducted to clarify the influence of

141 radiocesium in forest-derived products, including mushrooms. Kaduka et al. (2006) analyzed the

$142{ }^{137} \mathrm{Cs}$ aggregated transfer factor from the soil to different mushrooms and showed that the

143 aggregated transfer factors depend on the mushroom's trophic group, biological family, genus, and

144 species (Bannai, Yoshida \& Muramatsu, 1994). Bulko et al. (2014) evaluated the ${ }^{137}$ Cs uptake by

145 forest-derived products in the Gomel region, which was the most heavily contaminated after the

146 Chernobyl accident, and found that the accumulation of ${ }^{137} \mathrm{Cs}$ in mushrooms and berries was

147 directly related to the radiocesium contamination density of the soil, which is accounted for both

148 by the form of the Chernobyl fallout and by the natural and climatic conditions that determine

149 variations in the availability of radionuclides in the soil.

150 Although the number of samples was limited, we found that 17 species showed relatively higher

151 concentrations of radiocesium and that five species showed relatively lower concentrations. This

152 suggests that the concentration of radiocesium might depend on the species of mushroom. Usually,

153 habitat varies depending on species. To determine the factors affecting radiocesium concentrations

154 in mushrooms, Yoshida and Muramatsu (1994) collected mushrooms and categorized them into 
155

156

157

158

159

160

161

162

163

164

165

166

167

168

169

170

171

172

four different groups according to the main habitat of their mycelia: wood, the litter layer, the surface soil layer $(0-5 \mathrm{~cm})$, and the following soil layer $(>5 \mathrm{~cm})$, and found that the surface soil layer group showed the highest average concentrations of ${ }^{137} \mathrm{Cs}$. They concluded that the habitat of the mycelium seemed to be one of the most important factors controlling radiocesium concentration in mushrooms. Since habitat is closely associated with each particular species, it is suspected that species type is also associated with radiocesium concentrations in mushrooms.

We calculated committed effective doses ranging from $0.256-3.748 \mu \mathrm{Sv}$ and $0.093-1.368 \mathrm{mSv}$, respectively, based on the average daily and annual intake of mushrooms. After the FNPP accident, the Japanese government established provisional regulation values for ${ }^{131} \mathrm{I}$ (300 Bq/kg for drinking water and milk, 2,000 Bq/kg for vegetables) and for ${ }^{134} \mathrm{Cs}$ and ${ }^{137} \mathrm{Cs}(200 \mathrm{~Bq} / \mathrm{kg}$ for drinking water and milk, $500 \mathrm{~Bq} / \mathrm{kg}$ for vegetables, grains, meat, fish, and eggs). Due to this strict food-control policy, internal exposure from radioactive cesium and radioactive iodine were relatively limited (Harada et al., 2012; Koizumi et al., 2012; Hayano et al., 2013). However, according to the experience after the Chernobyl accident, excess intake of contaminated mushrooms is a risk factor for internal radiation exposure among residents. Hoshi et al. (2000) conducted measurements of the ${ }^{137} \mathrm{Cs}$ body burden in 1991-1996 for children residing in Bryansk Oblast (Russian Federation), an area that experienced contamination following the Chernobyl accident, and discovered that the most common food items contributing to ${ }^{137} \mathrm{Cs}$ intake in children were mushrooms, meat, milk, and 
173 vegetables. Travnikova et al. (2001) also found that the individual content of ${ }^{137} \mathrm{Cs}$ in the bodies of

174 inhabitants of a village in Bryansk Oblast correlated with their consumption of milk during the

175 initial period after the accident and with their consumption of forest mushrooms during the

176 subsequent period. Although our results showed that committed effective doses were relatively

177 limited even if residents ate contaminated foods several times, a long-term risk evaluation for the

178 internal radiation exposure of these individuals is needed in order to gain a better understanding of

179 radiation safety in Fukushima.

180 There are several limitations of this study. First, it was conducted only in Kawauchi Village for one

181 year. Second, we could not evaluate the relationship between radiocesium concentrations in

182 mushrooms and soil, due to insufficient soil samples. Further comprehensive studies are necessary

183 to evaluate the concentrations of radiocesium in mushrooms in Fukushima after the FNPP accident.

185 Conclusions

186 We evaluated radiocesium concentrations in wild mushrooms collected at Kawauchi Village in

187 Fukushima Prefecture and found that radiocesium exists in wild mushrooms at a relatively high

188 frequency. Although committed effective doses are relatively limited even if residents eat contaminated foods several times, we believe that comprehensive risk-communication based on measurements of radiocesium in the food and water, as well as in the soil, is necessary for the 
191 recovery of Fukushima after the nuclear disaster.

192 
194

195

196

197

198

199

200

201

202

\section{References}

Bannai T, Yoshida S, Muramatsu Y. 1994. Cultivation experiments on uptake of radionuclides by mushrooms. Radioisotopes 43:77-82 (in Japanese)

Bulko NI, Shabaleva MA, Kozlov AK, Tolkacheva NV, Mashkov IA. 2014. The ${ }^{137}$ Cs accumulation by forest-derived products in the Gomel region. Journal of Environmental Radioactivity 127:150-154. DOI: 10.1016/j.jenvrad.2013.02.003

Guillén J, Baeza A. 2014. Radioactivity in mushrooms: A health hazard? Food Chemistry 154:14-25. DOI: 10.1016/j.foodchem.2013.12.083

Hamada N, Ogino H, Fujimichi Y. 2012. Safety regulations of food and water implemented in the first year following the Fukushima nuclear accident. Journal of Radiation Research 53:641671. DOI: $10.1093 / \mathrm{jrr} / \mathrm{rrs} 032$

Harada KH, Fujii Y, Adachi A, Tsukidate A, Asai F, Koizumi A. 2012. Dietary intake of radiocesium in adult residents in Fukushima Prefecture and neighboring regions after the Fukushima Nuclear Power Plant accident: 24-h food-duplicate survey in December 2011. Environmental Science \& Technology 47. DOI: 2520-610 :10.1021/es304128t

Hayano RS, Tsubokura M, Miyazaki M, Satou H, Sato K, Sakuma Y. 2013. Internal radiocesium 
210 contamination of adults and children in Fukushima 7 to 20 months after the Fukushima NPP

211 accident as measured by extensive whole-body-counter survey. Proceedings of the Japan

212 Academy, Series B 89:157-163. DOI: 10.2183/pjab.89.157

213 Hille R, Hill P, Heinemann K, Ramzaev V, Barkovski A, Konoplia V, Neth R. 2000. Current

214 development of the human and environmental contamination in the Bryansk-Gomel Spot after

215 the Chernobyl accident. Radiation and Environmental Bbiophysics 39:99-109. DOI:

$216 \quad 10.1007 / \mathrm{s} 004110000043$

217 Hoshi M, Konstantinov YO, Evdeeva TY, Kovalev AI, Aksenov AS, Koulikova NV, Sato H,

218 Takatsui T, Takada J, Endo S, Shibata Y, Yamashita S. 2000. Radiocesium in children residing

219 in the western districts of the Bryansk Oblast from 1991-1996. Health Physics 79:182-186. DOI:

$220 \quad 10.1097 / 00004032-200008000-00011$

221 International Commission on Radiological Protection (ICRP). 1995. Age-dependent doses to the

222 members of the public from intake of radionuclides - Part 5. Compilation of Ingestion and

223 Inhalation Coefficients, ICRP Publication 72. Ann. ICRP 26

224 Jesko T, Zvonova I, Balonov M, Thornberg C, Mattsson S, Wallstrom E, Vesanen R, Alpsten M.

225 2000. Age-dependent dynamics of cesium radionuclide content in inhabitants of the Bryansk 
226 region, Russia: A seven-year study. Radiation Protection Dosimetry 89:179-182

227 Kaduka MV, Shutov VN, Bruk GY, Balonov MI, Brown JE, Strand P. 2006. Soil-dependent

228 uptake of ${ }^{137} \mathrm{Cs}$ by mushrooms: Experimental study in the Chernobyl accident areas. Journal of

229 Environmental Radioactivity 89:199-211. DOI: 0.1016/j.jenvrad.2006.05.001

230 Koizumi A, Harada KH, Niisoe T, Adachi A, Fujii Y, Hitomi T, Kobayashi H, Wada Y,

231 Watanabe T, Ishikawa H. 2012. Preliminary assessment of ecological exposure of adult residents

232 in Fukushima Prefecture to radioactive cesium through ingestion and inhalation. Environmental

233 Health and Preventive Medicine 17:292-298. DOI: 10.1007/s12199-011-0251-9

234 Merz S, Shozugawa K, Steinhauser G. 2015. Analysis of Japanese radionuclide monitoring data 235 of food before and after the Fukushima nuclear accident. Environmental Science \& Technology

236 49:2875-2885. DOI: 10.1021/es5057648

237 Merz S, Steinhauser G, Hamada N. 2013. Anthropogenic radionuclides in Japanese food:

238 Environmental and legal implications. Environmental Science \& Technology 47:1248-1256.

239 DOI: 10.1021/es3037498

240 Ministry of Health, Labour and Welfare (MHLW). 2012. National Health and Nutrition Survey

241 Nuclear Emergency Response Headquarters, Government of Japan. 2011. Additional Report of 
242 the Japanese Government to the IAEA — The accident at TEPCO's Fukushima nuclear power

243 stations

(Second

Report).

Available

at

244 http://www.iaea.org/sites/default/files/japanreport120911.pdf (accessed 30 August 2015)

245 Orita M, Hayashida N, Urata H, Shinkawa T, Endo Y, Takamura N. 2013. Determinants for the

246 return to hometowns after the accident at Fukushima Dai-ichi Nuclear Power Plant: A case study

247 for the village of Kawauchi. Radiation Protection Dosimetry 156:383-385. DOI:

$248 \quad 10.1093 / \mathrm{rpd} / \mathrm{nct} 082$

249 Report of Japanese Government to IAEA Ministerial Conference on Nuclear Safety — Accident

250 at TEPCO's Fukushima nuclear power stations. 2014. Available at

251 http://www.iaea.org/newscenter/focus/fukushima/japan-report (accessed 30 August 2015)

252 Sekitani Y, Hayashida N, Karevskaya IV, Vasilitsova OA, Kozlovsky A, Omiya M, Yamashita S,

253 Takamura N. 2010. Evaluation of ${ }^{137} \mathrm{Cs}$ body burden in inhabitants of Bryansk Oblast, Russian

254 Federation, where a high incidence of thyroid cancer was observed after the accident at the

255 Chernobyl nuclear power plant. Radiation Protection Dosimetry 141:36-42. DOI:

$256 \quad 10.1093 / \mathrm{rpd} / \mathrm{ncq} 137$

257 Skuterud L, Travnikova IG, Balonov MI, Strand P, Howard BJ. 1997. Contribution of fungi to 
258 radiocesium intake by rural populations in Russia. Science of the Total Environment 193:237-

259 242. DOI: 10.1016/S0048-9697(96)05346-6

260 Taira Y, Hayashida N, Orita M, Yamaguchi H, Ide J, Endo Y, Yamashita S, Takamura N. 2014.

261 Evaluation of environmental contamination and estimated exposure doses after residents return

262 home in Kawauchi Village, Fukushima Prefecture. Environmental Science \& Technology

263 48:4556-4563. DOI: 10.1021/es404534y

264 Travnikova IG, Bruk GJ, Shutov VN, Bazjukin AB, Balonov MI, Rahola T, Tillander M. 2001.

265 Contribution of different foodstuffs to the internal exposure of rural inhabitants in Russia after

266 the Chernobyl accident. Radiation Protection Dosimetry 93:331-339

267 United Nations Scientific Committee on the Effects of Atomic Radiation (UNSCEAR). 2013.

268 Sources, effects and risks of ionizing radiation. Report to the General Assembly, Scientific Annex

269 A: Levels and effects of radiation exposure due to the nuclear accident after the 2011 Great

270 East-Japan Earthquake and Tsunami, Volume I. Available at

271 http://www.unscear.org/docs/reports/2013/13-85418_Report_2013_Annex_A.pdf (accessed 30

272 August 2015)

273 Yoshida S, Muramatsu Y. 1994. Accumulation of radiocesium in basidiomycetes collected from 
274 Japanese forests. Science of the Total Environment 157:197-205 
276 Figure Legend

277

278 Figure 1: Location of Kawauchi Village, Fukushima Prefecture

279 Figure 2: Distribution of radiocesium concentrations $\left({ }^{134} \mathrm{Cs}+{ }^{137} \mathrm{Cs}\right)$ in mushrooms

280 Figure 3: Map of mushroom concentrations in Kawauchi Village 


\section{Table 1 (on next page)}

mushroom list

Concentrations of radiocesium in wild mushrooms 
Table 1. Concentrations of radiocesium in wild mushrooms

Species (habitat)

Sarcodon aspratus (surface soil)

Hypholoma sublateritium (wood)

Armillaria mellea (wood)

Tricholoma matsutake (surface soil)

Pholiota microspore (wood)

Lyophyllum shimeji (surface soil)

Lyophyllum decastes (surface soil)

Cortinarius salor Fr. (surface soil)

Boletopsis leucomelas (surface soil)

Pholiota squarrosa (wood)

Hygrophorus russula (surface soil) 5,719.4)

Grifola frondosa (wood)

Phaeolepiota aurea (surface soil)

Suillus bovinus(surface soil)

Lyophyllum fumosum (surface soil)

Lepista sordida (surface soil)

Lepista nuda (surface soil)

Panellus serotinus (wood)

Pleurotus ostreatus (wood)

Lentinula edodes (wood)

Armillaria tabescens (wood)

\begin{tabular}{|c|c|c|c|c|c|}
\hline $\mathrm{n}$ & ${ }^{134} \mathrm{Cs}^{*}$ & ${ }^{134} \mathrm{Cs}(\mathrm{Bq} / \mathrm{kg})^{* *}$ & \multicolumn{2}{|l|}{${ }^{137} \mathrm{Cs}^{*}$} & ${ }^{137} \mathrm{Cs}(\mathrm{Bq} / \mathrm{kg})^{* *}$ \\
\hline 79 & 79 & $290.8(43.8-1,870.1)$ & \multicolumn{2}{|l|}{79} & $667.5(126.8-4,504.5)$ \\
\hline 11 & 9 & $177.5(10.3-509.2)$ & \multicolumn{2}{|l|}{10} & $388.3(22.4-1,087.9)$ \\
\hline 10 & 6 & $46.3(31.1-189.7)$ & \multicolumn{2}{|l|}{8} & $69.8(16.9-394.5)$ \\
\hline 6 & 6 & $139.8(70.0-491.4)$ & \multicolumn{2}{|l|}{6} & $299.6(177.5-1171.2)$ \\
\hline 6 & 6 & $298.9(74.5-1,706.3)$ & \multicolumn{2}{|l|}{6} & $652.5(185.6-3,685.5)$ \\
\hline 5 & 3 & $89.8(64.8-107.0)$ & \multicolumn{2}{|l|}{4} & $164.5(95.7-193.8)$ \\
\hline 5 & 1 & 18.4 & \multicolumn{2}{|l|}{2} & $16.7(15.4-17.9)$ \\
\hline 4 & 4 & $3,596.8(363.1-5,432.7)$ & \multicolumn{2}{|l|}{4} & 7,589.4(802.6-11,616.2) \\
\hline 4 & 4 & $191.3(69.7-763.0)$ & \multicolumn{2}{|l|}{4} & $444.3(180.2-1,760.9)$ \\
\hline 4 & 0 & ND & \multicolumn{2}{|l|}{1} & 56.0 \\
\hline & 3 & \multicolumn{2}{|c|}{$415.0(319.4-2,661.5)$} & 3 & $986.9 \quad(727.6-$ \\
\hline 3 & 0 & ND & 0 & & ND \\
\hline 3 & 0 & ND & 0 & & ND \\
\hline 2 & 2 & $631.3(587.0-675.7)$ & 2 & & $1352.7(1,272.2-1,433.3)$ \\
\hline 2 & 2 & $84.4(68.1-100.6)$ & 2 & & 153.4 (93.8-212.9) \\
\hline 1 & 1 & $4,927.7$ & 1 & & $10,415.0$ \\
\hline 1 & 1 & $2,975.7$ & 1 & & $6,429.2$ \\
\hline 1 & 1 & 35.5 & 1 & & 88.7 \\
\hline 1 & 1 & 23.5 & 1 & & 57.2 \\
\hline 1 & 0 & ND & 0 & & ND \\
\hline 1 & 0 & ND & 0 & & ND \\
\hline
\end{tabular}


$29 *$ Number of detected mushrooms

$30 * *$ Median (minimum-maximum)

31 ND: not detected 
Table 2 (on next page)

committed effective dose

Committed effective dose due to wild mushroom intake 
Table 2. Committed effective dose due to wild mushroom intake

$\begin{array}{lll}\text { Species } & \mathrm{n} & \mathrm{mSv} / \mathrm{year} * \\ \text { Sarcodon aspratus } & 79 & 0.09(0.02-0.59) \\ \text { Hypholoma sublateritium } & 10 & 0.05(<0.01-0.15) \\ \text { Armillaria mellea } & 8 & 0.01(<0.01-0.05) \\ \text { Tricholoma matsutake } & 6 & 0.04(0.02-0.15) \\ \text { Pholiota microspora } & 6 & 0.09(0.02-0.50) \\ \text { Lyophyllum shimeji } & 4 & 0.03(0.01-0.03) \\ \text { Lyophyllum decastes } & 2 & <0.01(<0.01-<0.01) \\ \text { Cortinarius salor Fr. } & 4 & 1.05(0.11-1.60) \\ \text { Boletopsis leucomelas } & 4 & 0.06(0.02-0.23) \\ \text { Pholiota squarrosa } & 1 & <0.01 \\ \text { Hygrophorus russula } & 3 & 0.13(0.10-0.78) \\ \text { Suillus bovinus } & 2 & 0.19(0.17-0.20) \\ \text { Lyophyllum fumosum } & 2 & 0.03(0.02-0.03) \\ \text { Lepista sordida } & 1 & 1.44 \\ \text { Lepista nuda } & 1 & 0.88 \\ \text { Panellus serotinus } & 1 & 0.01 \\ \text { Pleurotus ostreatus } & 1 & 0.01 \\ \text { *Median (minimum-maximum) } & & \\ & & \end{array}$


1

Map of Kawauchi village

Location of Kawauchi Village, Fukushima Prefecture

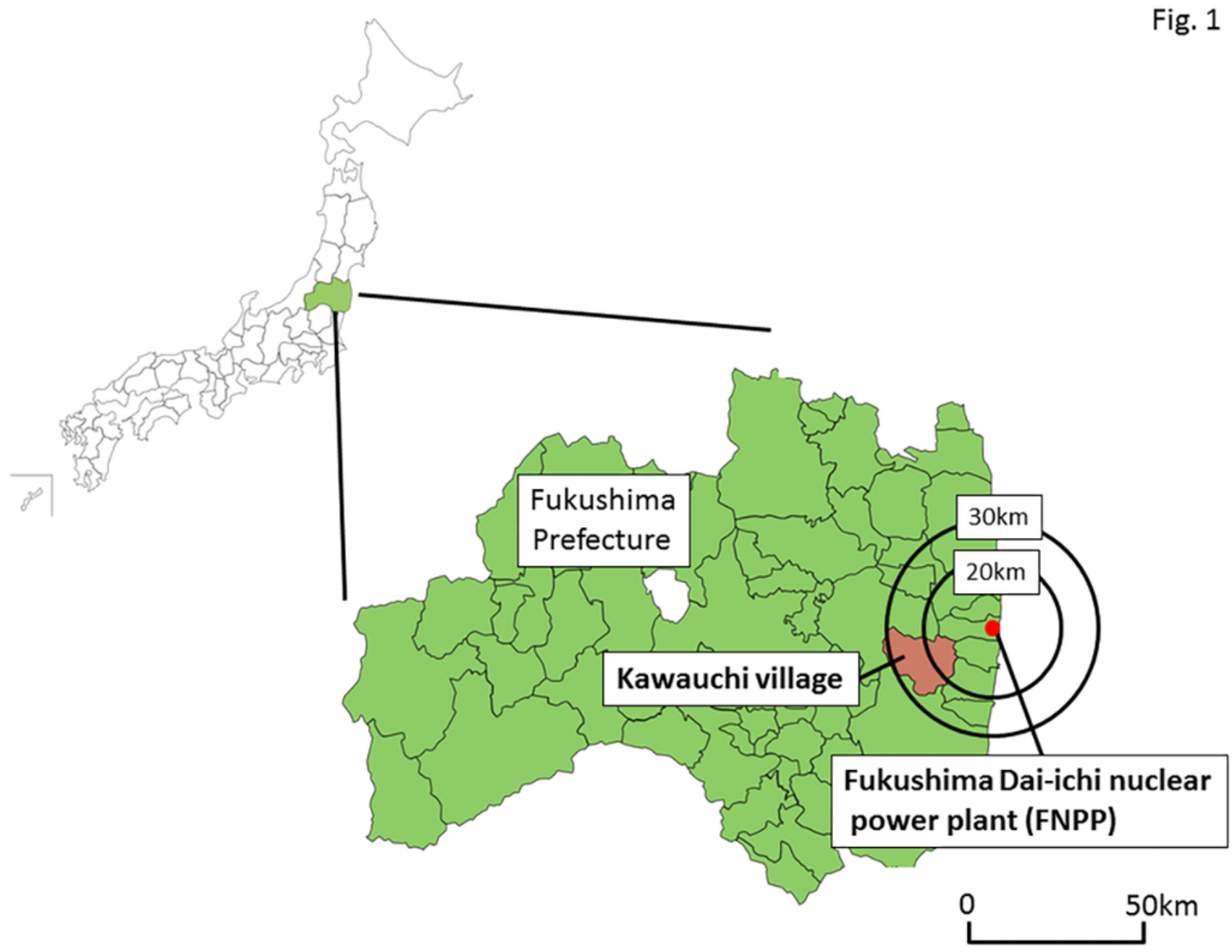


2

dried and raw mushrooms

Relationship of radiocesium concentrations between dried and raw mushrooms.

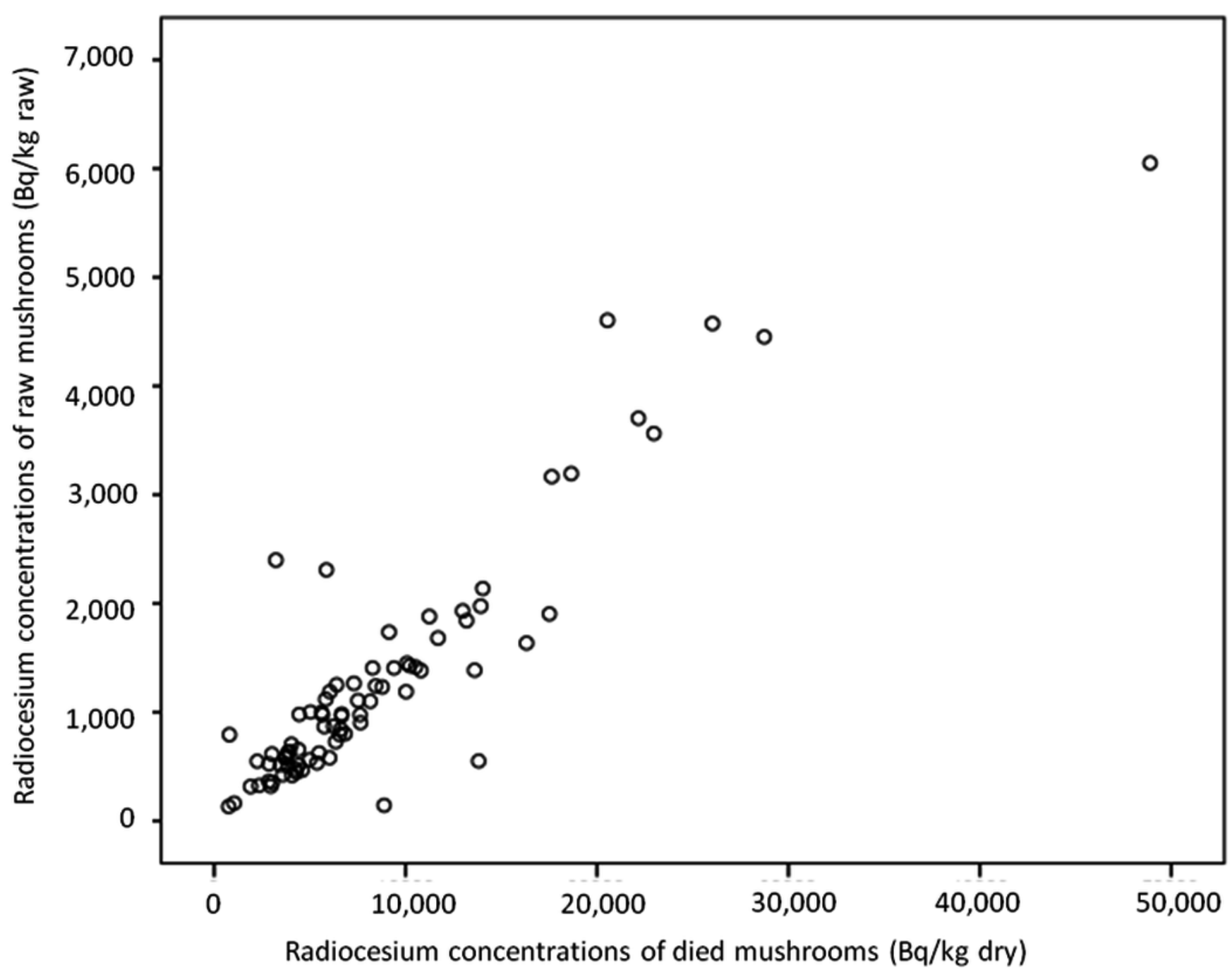


3

all mushrooms

Distribution of radiocesium concentrations (134Cs $+137 \mathrm{Cs})$ in all mushrooms

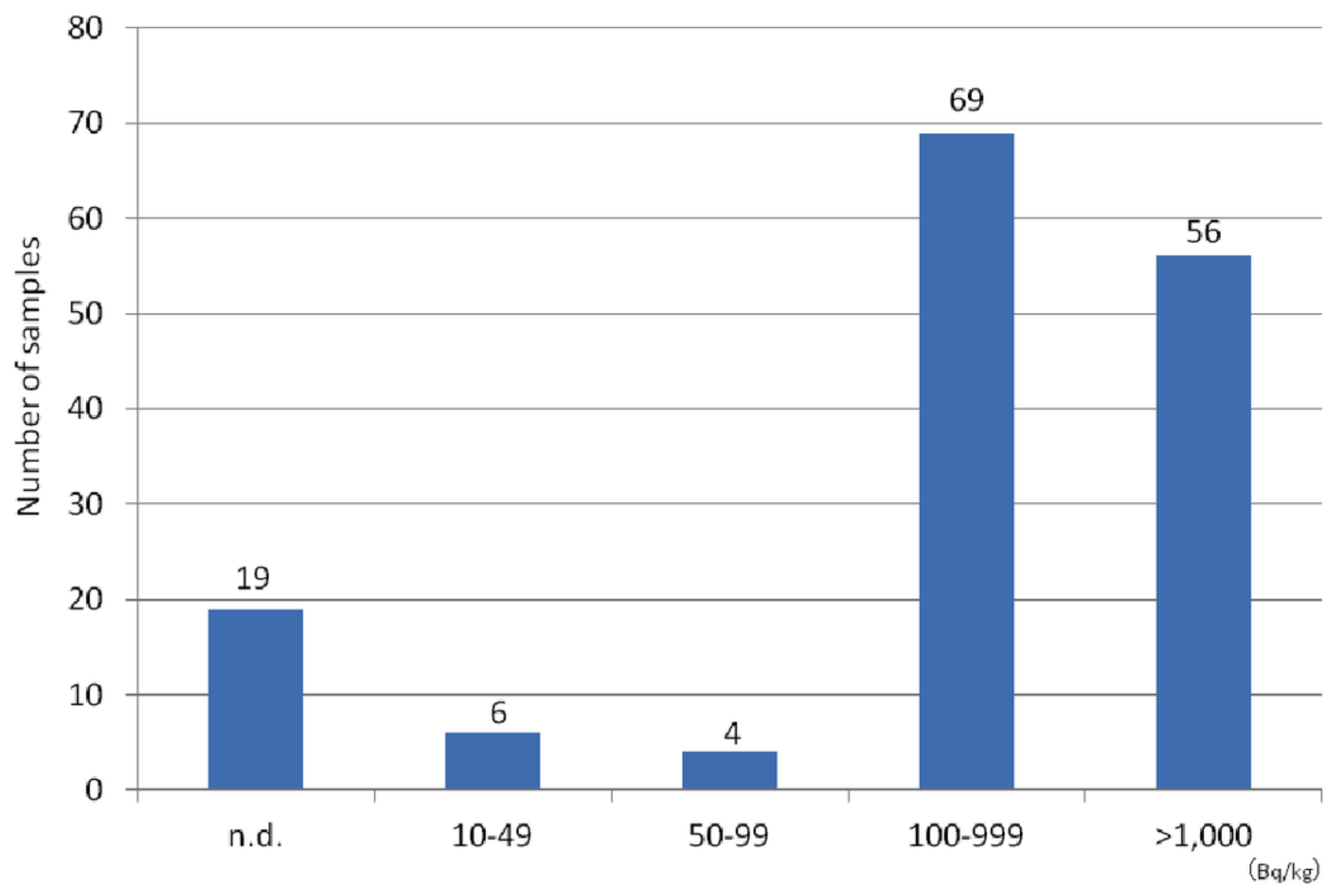


4

Sarcodon aspratus

Distribution of radiocesium concentrations (134Cs $+137 \mathrm{Cs})$ in Sarcodon aspratus.

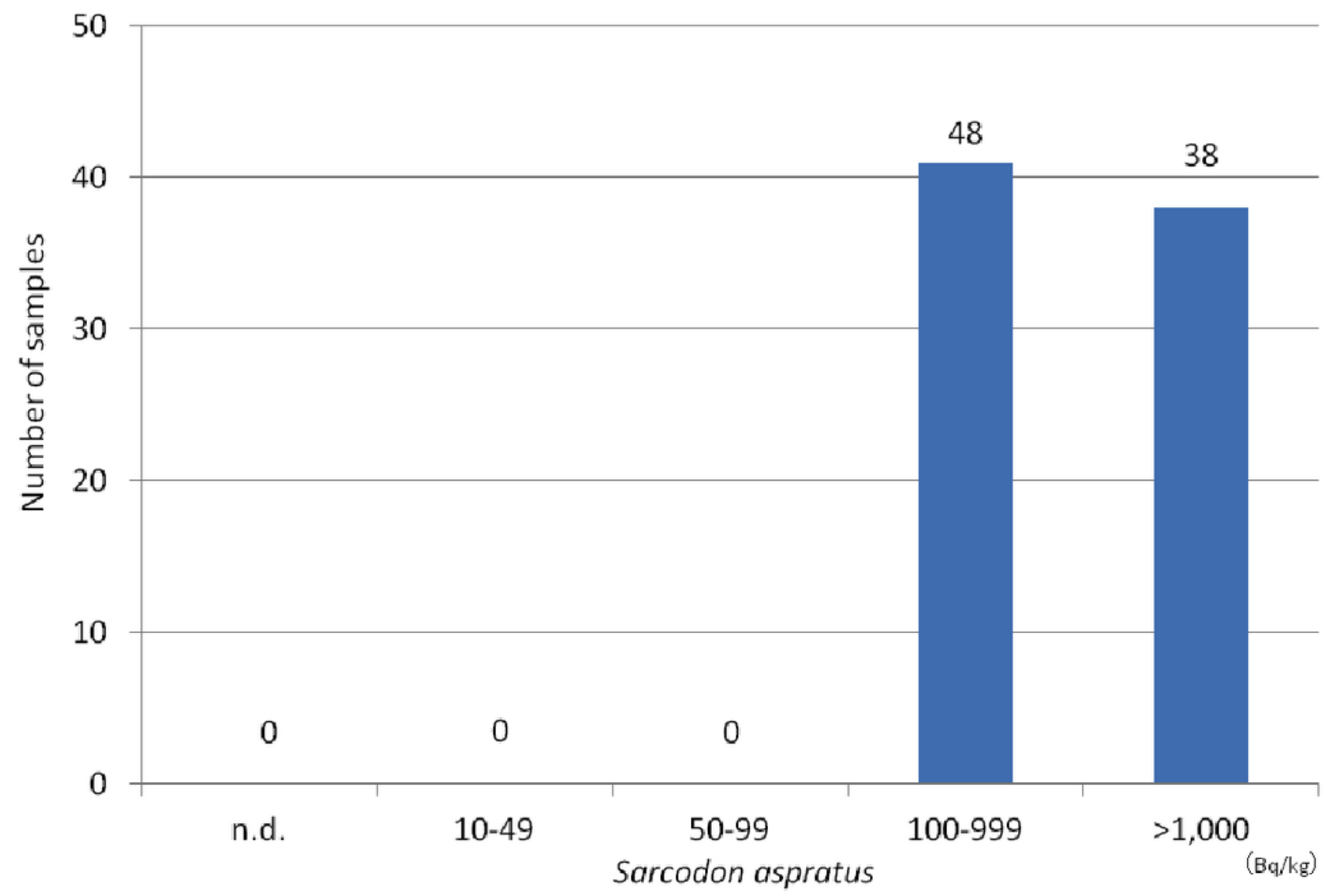




\section{5}

other mushrooms

Distribution of radiocesium concentrations (134Cs $+137 \mathrm{Cs})$ in other mushrooms.

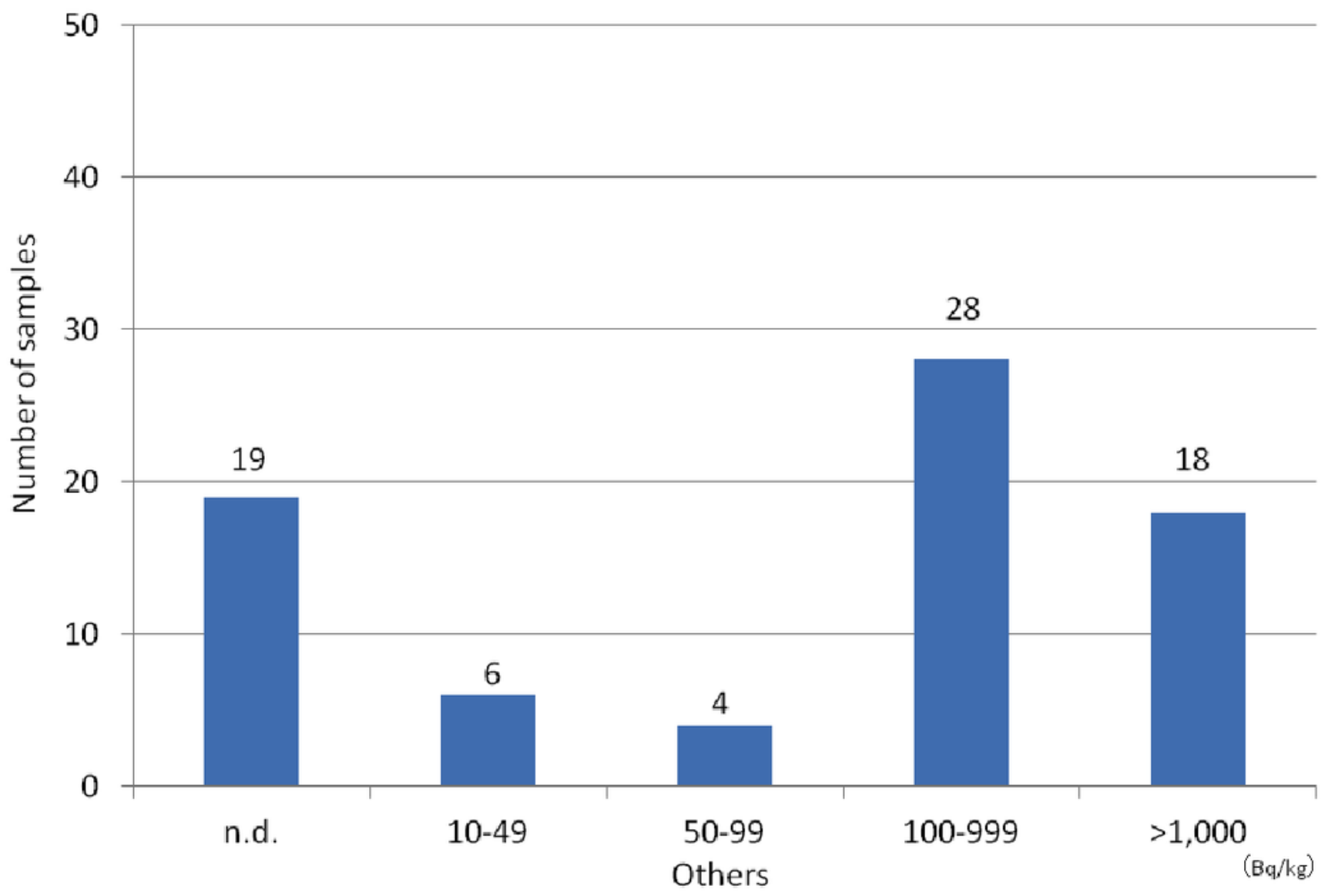


6

mushroom map

Map of mushroom concentrations in Kawauchi Village

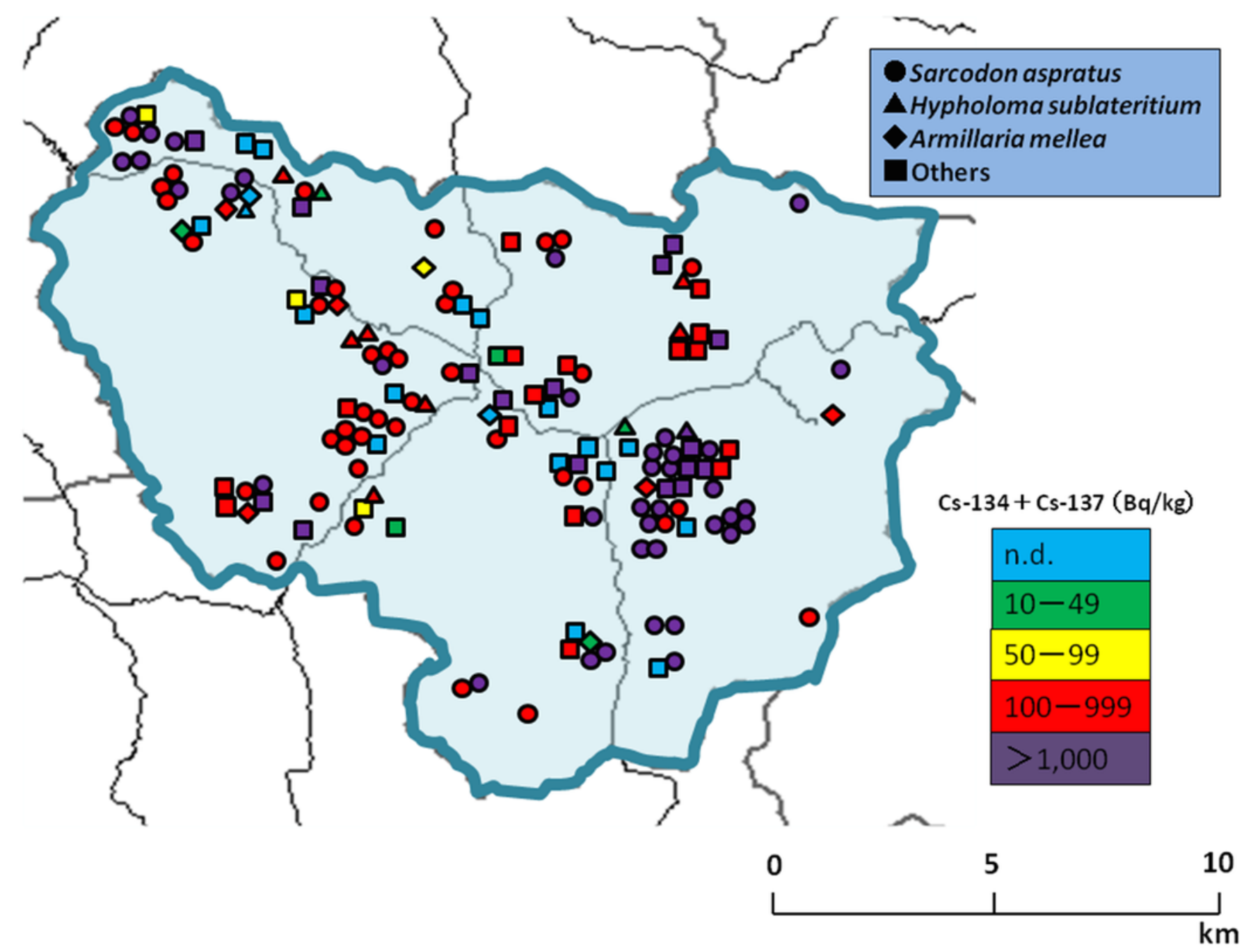

